\title{
Using mixed methods in clients with spinal cord injury to promote a smooth transition from hospital to society
} Hsiao-Yu Chen

\author{
Address: Department of Eldercare, Central Taiwan University of Science and Technology, Taiwan \\ from $5^{\text {th }}$ International Conference on Conservative Management of Spinal Deformities \\ Athens, Greece. 3-5 April 2008 \\ Published: 15 January 2009 \\ Scoliosis 2009, 4(Suppl I):P2 doi:I0.II86/1748-7|6I-4-SI-P2
}

This abstract is available from: http://www.scoliosisjournal.com/content/4/SI/P2

(C) 2009 Chen; licensee BioMed Central Ltd.

\section{Purpose}

To discover the features needed to progress and to identify which factors promote a smooth transition from hospital to society.

\section{Methods}

A mixed method design was used, which combined qualitative (Parse research method) and quantitative research strategies. Phase 1 , the parse research method was used on 15 participants with spinal cord injuries. The central finding of this phase was the following: the experience of moving forward is a triumph over handicaps. This occurs due to a transition of thoughts amid an open mind and due to a confirmation of self-worth emerging from faith. Phase 2, the purpose of this phase was to gain an understanding of how smooth transition clients function with their spinal cord injury. This was accomplished through data collection and analysis. The conceptual framework was build up through the result of phase 1 and literature review. The questionnaire was designed sequentially within the qualitative research, including demographic data, characteristics of the spinal cord injury, clients' selfperception, self-efficacy scale and social support. Four targets local Spinal Injury Association were drawn on the basis of cluster random sampling from the total of 23 Taiwan Spinal Injury Association. The participants were selected from each association through convenience sampling. The total number of participants is 210 .

\section{Results}

The results show that 164 participants $(80 \%)$ have moved forward already, and the others have not. There were significant correlations between moving forward and clients' self-perception, and self-efficacy. The findings are stronger when you combine a system of hospital and society to promote clients smooth transition. Finally, the continu- ing care and long-term service system is established. The nursing philosophy is extended from client-family centered care to the whole society.

\section{References}

I. Chen H-Y, Boore JRP: Considering the physiological and psychological consequences of spinal cord injury. British Journal of Neuroscience Nursing 2005, I :225-232.

2. Kroll T, Neri MT, Miller K: Using mixed methods in disability and rehabilitation research. Rehabilitation Nursing 2005, 30:106-113.

3. Middleton JW, Tate RL, Geraghty TJ: Self-efficacy and spinal cord injury: Psychometric properties of a new scale. Rehabilitation Psychology 2003, 48:28I-288. 